\title{
How anxious did you feel during lockdown? The roles resilience, living environment, and gender play on the level of anxiety state during pandemic isolation
}

Violeta Stefania Rotărescu, Diana Bianca Matei, Ioana Alexandra Mircea, Andreea Maria Mirescu, Bogdan George Nedelescu, Daniela Georgiana Nedelea, Alexandra Nicoleta Raluca Neagu, Alexandru George Necșulescu, Gabriel Angelo Oteșanu, Lucian Constantin Tudor

Memory Laboratory, University of Bucharest, Romania

\begin{abstract}
In the unique context of the coronavirus disease 2019 (COVID-19) pandemic, researchers and clinicians alike drew attention to the risks involved by physical and social isolation for mental health. Factors like resilience, gender, urban/rural environment, or preexisting anxiety can impact anxious states produced by home forced isolation. Based on these, we assumed that: i) there are significant differences in the level of anxiety (state) during the pandemic, depending on the living area of the subjects; ii) gender plays a moderating role in the relationship between resilience and anxiety; and iii) anxiety (trait), experiential avoidance, resilience, and family connectedness, determine the level of anxiety (state). The MemoryLab team conducted the present study on 495 subjects ( $\mathrm{n}=411$ women, age between 18 and 65$)$. Of these, 350 live in large and medium urban areas, 63 in small urban areas, and 82 in rural areas. As instruments, we used The State-Trait Anxiety Inventory (STAI 2.0), The Acceptance and Action Questionnaire 2 (AAQ-2), The Aggression Questionnaire (AQ), The Family Connectedness Questionnaire, and Connor-Davidson Resilience Scale 10 (CD-RISC-10), as well as the standard division of living areas according to community size. Data collection took place online during the spring peak of the pandemic. According to ANOVA analysis, people living in small urban areas have a higher level of anxiety. The difference is significant compared to those living in large and medium cities and villages. Gender has no moderating role in the relationship between resilience and the anxiety state. Also, experiential avoidance, anxiety (trait), and resilience play a significant role on the level of anxiety (state), measured during social isolation. The results could be an important indicator for understanding psychological mechanisms guiding interventions to support the communities effectively.
\end{abstract}

Key words: Anxiety state and trait; resilience; living environment; gender; family connectedness.

\section{Introduction}

The coronavirus disease 2019 (COVID-19) pandemic triggered one of the largest crises humanity has faced in

Correspondence: Violeta Stefania Rotărescu, Memory Laboratory, University of Bucharest, 90 Panduri Street, Bucharest, Romania. E-mail: violeta.rotarescu@fpse.unibuc.ro

Citation: Rotărescu, V. S., Matei, D. B., Mircea, I. A., Mirescu, A. M., Nedelescu, B. G., Nedelea, D. G., Neagu, A. N. R., Necșulescu, A. G., Oteşanu, G. A., \& Tudor L. C. (2020). How anxious did you feel during lockdown? The roles resilience, living environment, and gender play on the level of anxiety state during pandemic isolation. Research in Psychotherapy: Psychopathology, Process and Outcome, 23(3), 231-238. doi: 10.4081/ripppo.2020.496

Received for publication: 9 September 2020

Accepted for publication: 26 November 2020.

This work is licensed under a Creative Commons Attribution NonCommercial 4.0 License (CC BY-NC 4.0).

${ }^{\circ}$ Copyright: the Author(s), 2020

Licensee PAGEPress, Italy

Research in Psychotherapy:

Psychopathology, Process and Outcome 2020; 23:231-238

doi:10.4081/ripppo.2020.496 the last century. Many issues - changes in the work environment, long-lasting physical and social isolation periods, insecurity caused by the possibility of infection or reinfection (To et al., 2020) with severe acute respiratory syndrome-coronavirus 2 (SARS-CoV-2), the unpredictability of the virus, and preexisting mental problems (Chew et al., 2020) - produced a significant negative emotional pressure on the social and individual levels. This burden is significant for most people, especially for those exhibiting higher emotional vulnerability (Luo, Guo, Yu, Jiang, \& Wang, 2020).

During the COVID-19 pandemic, factors such as social and family connectedness, known for their role in counterbalancing job-related problems (Cowling et al., 2010; Chew et al., 2020), have been considerably diminished (Luo et al., 2020).

This situation exerted more pressure on the individual's economic, mental and emotional resources needed to cope with the upcoming issues resulting from the pandemic. Up until now, research has measured personal changes in times of prolonged stress (Chew et al., 2020) or in periods of physical (Bennet, 1983) and social isolation (Cowling et al., 2010) and was conducted either by simulating restrictive conditions (Pagel \& Choukèr, 2016) or for shorter pandemic periods (Cowling et al., 2010). 
We have relatively little information about how people react to pandemic threats (Madhav et al., 2017). Some studies have addressed people's emotional reactivity during MERS or AH1N1 outbreaks (Cowling et al., 2010; Wheaton et al., 2012). Others assessed the emotional state of economically (Douglas et al., 2020) or educationally affected communities (idem) by such situations and the significant changes due to these epidemics.

A common element from the previous outbreaks, which also occurred throughout the current pandemic, is the significant alteration of the emotional state (APA, 2020).

Anxiety plays a crucial role in our study. We consider it to be the primary emotional response facing the challenges of the pandemic. Psychologically, the term anxiety is a broad concept covering a wide range of negative emotions and thoughts, characterized by inner unpleasantness, feelings of insecurity, and increased arousal, often accompanied by an irregular behavior pattern when worrying over current or anticipated events.

There are two types of anxiety: state anxiety, meaning the anxiety experienced by an individual at a particular moment in time, which increases in the presence of an anxiogenic stimulus (Lister, 1990), and trait anxiety, meaning the anxiety which is consistent over time.

Recent neuroscientific research strengthens this separation theory, showing that different brain areas become active in people with high scores either on the anxiety trait or anxiety state (Saviola et al., 2020; Sylvester et al., 2012). However, the two types have a close interaction, especially during threatening situations (Leal et al., 2017). Under the circumstances of perceived or real threats, state and trait anxiety seem to interact closely and mutually (Leal et al., 2017).

The trait anxiety has a genetic basis, with a consistent family aggregation (Hettema et al., 2001), especially in generalized anxiety and phobic disorders. Exogenous factors play an equally important role, and among them, we can distinguish interactions with family members (ibidem) and physical activity (Hegberg \& Tone, 2015). Unlike the trait, which is relatively stable over time, many other factors, exogenous and endogenous alike, influence the anxiety (state). New, unfamiliar, unexpected, or stressful situations may increase anxiety levels (Douglas et al., 2020).

The residence place is considered one of the factors associated with anxiety and mental health (Schiele \& Domschke, 2018). The living environment strongly correlates with stress, quality of life, and the presence and intensity of mental illness. Cities, in particular, are associated with a sharper deterioration of the mental state and well-being (White, Alcock, Wheeler, \& Depledge, 2013). However, individual characteristics determine the degree of the urban environment's negative influence (Verheij, 1996), while green areas in cities seem to improve mental health and quality of life (de Vries, Verheij, Groenewegen, \& Spreeuwenberg, 2003). Living place is one of the factors frequently related to adolescent anxiety and depression (Hesketh \& Ding, 2005; Malaquias, Crespo, \& Francisco, 2015). These pathologies appear to be more common in rural areas compared to urban ones. Girls seem to be more prone to depression than boys, while, in terms of anxiety, there are no significant differences between the two genders (Hesketh \& Ding, 2005).

The living environment's role is more prominent in situations like pandemic. Its influence on an individual's health hits new values (Zerbe, Parkerson, \& Spitzer, 1994). Under these conditions, the rural environment, usually associated with fewer resources for healthcare (the lack of specialty doctors and psychologists) (Wainer \& Chesters, 2000), becomes compensated by a genuinely healthy environment due to the green space around the house, as well as the presence of some determinants of resilience, such as social connectivity and economic participation (ibidem). Also, the restrictions on individual movement imposed by the COVID-19 sanitary measures didn't affect the people living in rural areas as much as those in urban areas due to the nature of living conditions. A similar but opposite influence regards urban housing, which becomes, in the frame of home work and travel restrictions, a real prison for its inhabitants (Bennet, 1983).

Experiential avoidance is another variable frequently associated with psychopathological manifestations, especially with depressive and anxiety disorders. Although experiential avoidance may be considered an emotional regulation strategy (Boulanger, Hayes, \& Pistorello, 2010), it also correlates with the development of specific pathologies (Roya, 2017). Furthermore, it mediates the impact of stressful events and the individual's ability to adapt to them, thus influencing life quality. Numerous studies indicate a significant association between experiential avoidance and symptoms of depression and anxiety (Mahoney, Segal, \& Coolidge, 2015), burnout (Iglesias, de Bengoa Vallejo, Salvadores Fuentes, 2010), or other psychopathologies (Fledderus, Bohlmeijer, \& Pieterse, 2010), both in young and older adults. Experiential avoidance in stressful times leads to an increased risk of developing psychopathology and a lower mental health level (ibidem). Also, it slows down physical recovery in the case of a somatic pathology (Ward, 2000), thus adding another side effect to the measures taken against the spread of SARS-CoV-2 infection. Under these conditions, it is reasonable to suppose that social isolation during the pandemic, under stress, could activate a maladaptive emotional regulation mechanism such as experiential avoidance (Shi, Zhang, Zhang, Fu, \& Wang, 2016).

Beside the risk factors, we also examined how the protective factors work against the anxiety related to COVID19 pandemic. Resilience is an essential protective psychological factor. It is a set of behaviors and attitudes that enable adaptive coping strategies in stressful situations and negative life events (Lamond et al., 2008). It is positively associated with psychological well-being and 
negatively associated with depression and anxiety (Haddadi \& Besharat, 2010).

Family connectedness is another protective psychological factor. It is a construct that explains how close and emotionally connected to their families individuals are. However, beyond its positive side, some aspects of the concept's cultural and social facets (Hardway \& Fuligni, 2006) and the genetic determination according to gender (Jacobson \& Rowe, 1999) still need to be clarified. Lack of family connectedness is considered a powerful predictor of behaviors like distress, suicide, violence, and substance use (Jacobson \& Rowe, 1999).

All factors have a different relationship with anxiety (state), so we should draw separate research questions. The living area is an important exogenous factor with a constant action during an individual's existence. Therefore, we aim to identify the impact of the environment on the level of anxiety. The influence of protective factors, such as resilience, on the anxiety level, could vary in stressful situations, depending on gender. Finally, all variables exert a simultaneous and unequal action on the level of anxiety experienced in pandemic conditions. Given all these, the research questions are: i) To what extent do people's anxious states differ, depending on the environment in which they live during the COVID-19 pandemic? ii) Can we talk about a moderating effect of gender on the relationship between resilience and anxiety? Does resilience affect anxiety in different ways in males compared to females? iii) What is the influence of preexisting anxiety (trait), as well as of emotional coping mechanisms, on the anxiety (state)?

\section{Methods}

The protocol is subject to compliance with current privacy legislation. The current data protection laws (EU GDPR 679/2016) are valid only for EU participants.

\section{Participants}

Four hundred ninety-five participants ( $\mathrm{n}=411$ women) took part in the study. According to age, the distribution of subjects is: 450 in the $18-25$ years old group, 30 in the 26-35 years old group, 13 in the 36-45 years old group, and 2 participants over 55 years. The demographic data show that the participants come from rural areas (localities with less than 5000 inhabitants, $n=82$ subjects), small urban areas (towns with a population between 5001 and 25,000 inhabitants, $n=63$ subjects), and medium and large metropolitan areas (cities with more than 25,001 inhabitants, $\mathrm{n}=350$ subjects).

\section{Procedure}

The design of this research is a cross-sectional one. The research team posted announcements regarding the study on several social media pages of the Faculty of Psy- chology and Educational Sciences, pages available to external visitors. People interested in participating in the research sent a message to the Memory Laboratory email address. The participants' email addresses were known by one Lab member responsible for the correspondence and were strictly used only for that purpose. Participants received and completed the set of questionnaires through Google Form after reading and agreeing to the informed consent form regarding their participation in the study. Data collection took place between April and May 2020, during the strict isolation period imposed by the national government. After the completion of the database, the research team deleted the emails.

\section{Measurements}

The variables were measured with self-report questionnaires, applied online through a Google form document. The instruments used were: STAI 2.0 Form Y for assessing trait and state anxiety, Connor-Davidson Resilience Scale (CD-RISC-10) - 10-item version for resilience measurement, Acceptance and Action Questionnaire (AAQ-2) for the assessment of experiential avoidance/psychological flexibility, and Family Connectedness Questionnaire (part of the Minnesota Student Survey 2004) for the assessment of family relationships. We also collected data about gender and living residence.

The State-Trait Anxiety Inventory Form Y (STAI - Y) STAI consists of 2 subscales (state anxiety and trait anxiety) comprising 20 items each, with negatively-keyed items being reverse-scored (Spielberger, 1983). Items have four response options scored from 0 (never/seldom) to 3 (always/almost always). The total score on each subscale is the sum of all item scores, ranging from 0 to 60 , higher scores corresponding to a higher level of anxiety (state or trait). For the present study, Cronbach alpha for State Anxiety was 0.96, and for Trait Anxiety was 0.94 .

The Connor - Davidson Resilience Scale (CD-RISC-10) - The CD-RISC 10 (Campbell-Sills, Forde, \& Stein, 2009) consists of 10 statements describing different sides of resilience: flexibility, sense of self-efficacy, ability to regulate emotion, optimism, and cognitive focus/maintaining attention under stress. The total score is obtained by summing all ten items and may range from 0 to 40 . Higher scores suggest a higher level of resilience. The 10 -item version proved to have, over multiple measurements, excellent reliability. Cronbach alpha for the present sample is 0.87 .

Acceptance and Action Questionnaire (AAQ - 2) - The AAQ-2 (Bond et al., 2011) is a 7-items questionnaire measuring experiential avoidance (higher scores) and psychological flexibility (lower scores). Participants completed the items using a 7-point Likert scale: 1 (not true) to 7 (entirely true). For the present study, Cronbach alpha is 0.92 .

Family Connectedness Scale (FCS) - Family Connectedness Scale is a questionnaire used in Minnesota Student Survey (2004) to measure family connectedness, viewed as a protective factor, between adolescents/young adults 
and their families (Eisenberg \& Resnick, 2006). Participants responded to a 7-items scale on a 4-point Likert scale ranging from 1 (strongly disagree) to 4 (strongly agree), with higher scores indicating greater levels of psychological connectedness between adolescents and their families. Cronbach alpha for the present sample is 0.88 .

The area of living was among the demographic questions, and it was evaluated by the local legislation (Law $351 / 2001$ ), which provides a classification of localities into six ranks - from rank 0 (capital of the country) to rank $\mathrm{V}$ (small villages and hamlets). For the sake of data analysis, we have reduced this classification into three categories, namely: i) Medium and large cities (with more than 25,000 inhabitants), ii) Small towns (inhabitants between 5001 and 25,000), iii) Villages (less than 5000 inhabitants).

\section{Results}

Data were collected online and analyzed with SPSS 25.

For the first hypothesis of the study, we used an ANOVA analysis (Table 1).
As it can be seen, there are significant differences in the level of anxiety measured between groups of subjects who lived in different environments during the pandemic. Subjects with a higher level of anxiety were those living in small towns. The differences between them and those in rural areas, respectively in medium and large cities, is significant $(\mathrm{P}=0.008$, respectively $\mathrm{P}=0.014)$. In contrast, there were no significant differences between subjects in medium and large urban areas and those in rural areas $(\mathrm{P}=1)$.

To verify the effect of gender on the relationship between resilience and anxiety level, we performed a moderation analysis (Table 2).

The above results indicate that, in our study, gender has no moderating effect on the relationship between resilience and the level of anxiety, which refutes the initial hypothesis.

To verify the third hypothesis, we used a linear regression model to check if experiential avoidance, trait anxiety, resilience, and family connectedness, as predictive variables, have a significant impact over the anxiety level. As seen in Table 3, the results validate a three-predictor

Table 1. The level of anxiety state depending on living environment (rural, small cities, and medium and large cities).

\begin{tabular}{llcccc}
\hline Living environment & & Mean difference (I-J) & Sig. & \multicolumn{2}{c}{$\mathbf{9 5 \%}$ confidence interval } \\
\cline { 2 - 6 } I & $\mathbf{J}$ & & \multicolumn{2}{c}{ Lower Bound } & Upper Bound \\
\hline 3. rural areas & 2. small urban areas & $-5.548^{*}$ & 0.008 & -9.96 & -1.14 \\
\hline & 1. medium and large urban areas & -1.281 & 1 & -4.5 & 1.93 \\
\hline 2. small urban areas & 3. rural areas & $5.548^{*}$ & 0.008 & 1.14 & 9.96 \\
\hline & 1. medium and large urban areas & $4.267^{*}$ & 0.014 & 0.66 & 7.88 \\
\hline 1. medium and large urban areas & 3. rural areas & 1.281 & 1 & -1.93 & 4.5 \\
\cline { 2 - 6 } & 2. small urban areas & $-4.267^{*}$ & 0.014 & -7.88 & -0.66 \\
\hline
\end{tabular}

*The mean difference is significant at the 0.05 level.

Table 2. Moderation analysis having gender as moderator in resilience - anxiety relation.

\begin{tabular}{cccccccc}
\hline & & R Square Change & df1 & df2 & \multicolumn{2}{c}{ Sig. F Change } \\
\hline 1 & $0.498^{\mathrm{a}}$ & 0.248 & 0.248 & 2 & 492 & 0.000 \\
\hline 2 & $0.499^{\mathrm{b}}$ & 0.249 & 0.000 & 1 & 491 & 0.606 \\
\hline
\end{tabular}

a. Predictors: (Constant), gender, resilience; b. Predictors: (Constant), gender, resilience, int_res_gen.

Table 3. Linear regression model of the variables determining the level of anxiety (state) during COVID-19 spring lockdown.

\begin{tabular}{lccccccc}
\hline Model & R & R Square & $\begin{array}{c}\text { Adjusted } \\
\text { R Square }\end{array}$ & $\begin{array}{c}\text { Std. Error } \\
\text { of the Estimate }\end{array}$ & $\begin{array}{c}\text { R Square } \\
\text { Change }\end{array}$ & $\begin{array}{c}\text { Change Statistics } \\
\text { df1 } \\
\text { df2 }\end{array}$ \\
\hline 1 & $0.601^{\mathrm{a}}$ & 0.361 & 0.36 & 8.799 & 0.361 & 4 \\
\hline 2 & $0.779^{\mathrm{b}}$ & 0.607 & 0.606 & 6.907 & 0.246 & 0 \\
\hline 3 & $0.783^{\mathrm{c}}$ & 0.614 & 0.611 & 6.855 & 0.007 & 1 \\
\hline 4 & $0.784^{\mathrm{d}}$ & 0.615 & 0.612 & 6.855 & 0.001 & 491 \\
\hline
\end{tabular}

a. Predictors: (Constant), AAQ; b. Predictors: (Constant), AAQ, STAI (trait); c. Predictors: (Constant), AAQ, STAI trait, resilience; d. Predictors: (Constant), AAQ, STAI trait, resilience, family connectedness. 
model. Their effects in determining the anxiety level are $36 \%$ for experiential avoidance, $24.6 \%$ for trait anxiety, and $0.7 \%$ for resilience. Family connectedness has a minor impact on anxiety ( $0.1 \%$ of the total variance), representing a statistically non-significant level. Overall, the proposed model explains $61.5 \%$ of the total variance of the anxious state.

\section{Discussion and Conclusions}

The current study aimed to examine which variables play an active role in the arousal of anxious state, a common emotional condition in the context of the SARS-Cov2 pandemic. Under these unusual circumstances, results could provide insights into improving and guiding future interventions targeting people's anxiety.

Results supported the first hypothesis, stating the existence of significant differences in the level of anxiety (state) during the pandemic, among subjects from different living places. Also, data supported a model where anxiety (trait), experiential avoidance, and resilience have a determining effect on the anxiety level (state). For the last hypothesis, there was no evidence indicating a moderating role of gender in the relationship between resilience and anxiety.

Regarding our first hypothesis, results showed significant differences in the anxiety level (state) between the participants living in small urban areas and those living either in medium or large metropolitan areas, or in rural areas. Even though there is no clear evidence suggesting a strong connection between urban areas and mental disorders, some studies have shown a link between the place of residence and a higher prevalence of anxiety and depression (McKenzie, Murray, \& Booth, 2013; Walters et al., 2004). Additionally, there is a considerable body of data showing that rural areas offer better opportunities for coping with stress (Thompson et al., 2012), fewer incidents of depression (Cohen-Cline, Turkheimer, \& Duncan, 2015), and decreased mortality rates (James, Hart, Banay, \& Laden, 2016). The economic uncertainty induced by the COVID19 pandemic and the different economic development of living areas could explain the results. According to the data provided by national agencies (INS, 2020; Comisia Naţională pentru Statistică și Prognoză, CNSP, 2019), the medium and large urban areas have the smallest number of unemployed workers, and draw more economic investments. At the same time, rural areas are quite stable economic environments, faced with a pandemic. People in villages continued living and working as usual, since social distance is part of the normal daily life, and economic conditions remained largely unchanged. The most affected areas were small towns, where the job offerings and social resources were already limited, leading to increased anxiety caused by the transition from employment to unemployment (McKee-Ryan, Song, Wanberg, \& Kinicki, 2005). Pandemic conditions limit even more the access of these communities to economic resources (Ajilore, 2020; Bartik et al., 2020) and create a psychological framework dominated by anxiety and fear (Taquet, Luciano, Geddes, \& Harrison, 2020). Our result could then be considered as a possible guide to a targeted intervention toward more affected communities.

Another objective of this study was to see if gender plays a moderating role in the relationship between resilience and anxiety (Connor \& Zhang, 2006; Min et al., 2012; Southwick et al., 2005 ; Zhang, Zhang, Zhang, Zhang, \& Feng, 2018). Some studies have shown that women have higher levels of anxiety (Hankin, Mermelstein, \& Roesch, 2007; Sanad, 2019; Savitsky, Findling, Ereli, \& Hendel, 2020) and react differently (Bekker \& van Mens-Verhulst, 2007) compared to men, who seem to be more resilient (Zhang et al., 2018). We expected a different reactivity of men, compared to women, during the COVID-19 spring peak. The gender differences were not statistically significant in our sample. This result is similar to the results obtained by studies done in China (Cao et al., 2020; Huang \& Zhao, 2020) at the beginning of the pandemic period. Other studies have shown that gender contributes to COVID-19-based anxiety, women being more anxious than men (Moghanibashi-Mansourieh, 2020). As for our sample, we have to consider the large disparity in gender distribution in our study (411 female subjects and only 84 male subjects). This fact might have influenced the outcome of the research.

For the third hypothesis, the linear regression shows that independent variables - experiential avoidance, anxiety (trait), and resilience - significantly impact the dependent variable, meaning the anxiety (state). Family connectedness has a minor effect on the level of anxiety, though. So, the initial model is partially confirmed. Experiential avoidance could lead to a lower ability to adjust to inevitable negative changes, or significant compliance requirements, similar to changes that did occur during the COVID-19 pandemic. Initially used as a handy defense mechanism, experiential avoidance creates a trigger for anxiety and poor adjustment to external requirements (Chawla \& Ostafin, 2007), distorting the individuals' cognitive and action responses. Regarding the influence of the preexisting anxiety (trait) on the level of anxiety (state), the results are similar to those from other studies (Leal et al., 2017).

One of the objectives of the study was to determine whether resilience significantly influences the anxiety (state). The regression model confirms the initial assumption. Experiential avoidance has a more significant impact, compared to resilience, on anxiety trait. This result suggests that a clinical approach to anxiety may be more effective if it addresses the decrease of experiential avoidance, rather than the increase of resilience. This might be an interesting result for those looking for a therapeutic approach because working on the decrease of experiential avoidance may be more effective in lowering anxiety.

Highlighting the role of family connectedness on anx- 
iety was another objective for us. As results show, family connectedness is not a significant predictor of anxiety state, invalidating the initial assumption. According to the results of our study, family is not perceived as a protective shield against the pandemic threat. For the current pandemic situation, close family ties did not contribute to the decrease of anxiety, due to the global character of the pandemic. The solution for such problems relies on authorities, not on close family members.

Although our study is amongst the first cross-sectional studies to measure the anxiety of individuals during the COVID-19 pandemic, with many participants from diverse backgrounds, it has a number of limitations that should be taken into account for future studies. First of all, the cross-sectional design itself brings certain limitations: without a longitudinal design, the cause-effect relationship between variables cannot be established, as the exposure and outcome are simultaneously assessed. Also, we cannot generalize the results over a long period of time, or on other populations besides the Romanian one. Another limit is the inequality of gender distribution. Our research includes a significantly higher number of female participants $(\mathrm{n}=411)$. This may provide an explanation for the invalidation of the hypothesis which stated that gender plays a moderating role in the relationship between resilience and anxiety. Third of all, while data collected from multiple backgrounds brings diversity, the living environment is unequally distributed among participants, most participants (350 out of 495) living in large urban areas. Finally, measuring variables through self-report questionnaires is another limit, because the answers can be exaggerated, respondents can be ashamed to reveal certain details, or the social desirability bias may appear.

In conclusion, the data obtained show that several factors significantly influence the emotional reactivity reported during the COVID-19 pandemic. The place of residence, seen both as a living environment and as a determining framework for the individual's quality of life, is directly involved in changing the level of anxiety. The more the environment restricts, the higher the level of fears and anxiety becomes. Pre-existing conditions and coping mechanisms also play a significant role in increasing the level of anxiety. Experiential avoidance has a much more substantial impact than resilience on the status of the anxious state. From this point of view, intervention to reduce this maladaptive emotional mechanism's action can lead to a better emotional response to unknown and difficult situations like the pandemic.

\section{References}

Ajilore, O. (2020). Rural America is starting to feel the impact of the coronavirus. Center for American Progress. Available from: https://www.americanprogress.org/issues/economy/reports/2020/04/28/484016/rural-america-starting-feel-impactcoronavirus/
American Psychological Association (APA). (2020). Psychological impact of COVID-19. Available from: https://www.apa. org/topics/COVID-19/psychological-impact

Bartik, A. W., Bertrand, M., Cullen, Z., Glaeser, E.L., Luca, M., \& Stanton, C. (2020). The impact of COVID-19 on small business outcomes and expectations. Proceedings of the $\mathrm{Na}$ tional Academy of Sciences of the United States of America, 117 (30), 17656-17666. doi: dwww.pnas.org/cgi/doi/10. 1073/pnas.2006991117.

Bekker, M. H. J., \& van Mens-Verhulst, J. (2007). Anxiety disorders: sex differences in prevalence, degree, and background, but gender-neutral treatment. Gender Medicine, 4(2), 178-193. doi: https://doi.org/10.1016/S1550-8579(07) 80057-X.

Bennett, S. A. (1983). Patient perspective - psychological effects of barrier nursing isolation. Australian Nursing Journal, 12(10), 36-37.

Bond, F. W., Hayes, S. C., Baer, R. A., Carpenter, K. M., Guenole, N., Orcutt, H. K., \& Zettle, R. D. (2011). Preliminary psychometric properties of the Acceptance and Action Questionnaire-II: A revised measure of psychological inflexibility and experiential avoidance. Behaviour Therapy, 42, 676-688. doi: https://doi.org/10.1016/j.beth.2011.03.007

Boulanger, J. L., Hayes, S. C., \& Pistorello, J. (2010). Experiential avoidance as a functional contextual concept. In Kring, A.M., \& Sloan, D.M. (Eds.), Emotion regulation, and psychopathology: A transdiagnostic approach to aetiology and treatment (pp. 107-136). New York, NY: The Guilford Press.

Campbell-Sills, L., Forde, D. R., \& Stein, M. B. (2009). Demographic and childhood environmental predictors of resilience in a community sample. Journal of Psychiatric Research, 43(12), 1007-1012. doi: https://doi.org/10.1016/j. jpsychires.2009.01.013

Cao, W., Fang, Z., Hou, G., Han, M., Xu, X., Dong, J., \& Zheng, J. (2020). The psychological impact of the COVID-19 epidemic on college students in China. Psychiatry Research, 112934. doi: https://doi.org/10.1016/j.psychres.2020.112934

Chawla, N., \& Ostafin, B. (2007). Experiential avoidance as a functional dimensional approach to psychopathology: An empirical review. Journal of clinical psychology, 63(9), 871890. doi: https://doi.org/10.1002/jclp.20400

Chew, Q. H., Wei, K. C., Vasoo, S., Chua, H. C., \& Sim, K. (2020). Narrative synthesis of psychological and coping responses towards emerging infectious disease outbreaks in the general population: practical considerations for the COVID-19 pandemic. Singapore medical journal, 61(7), 350-356. doi: https://doi.org/10.11622/smedj.2020046

Comisia Națională pentru Statistică și Prognoză (CNSP) [National Board of Strategy and Prognosis]. (2019). Proiecţia principalilor indicatori economico-sociali în PROFIL TERITORIAL până în 2023. Available from: http://www.cnp.ro/ user/repository/prognoze/Prognoza_profil_teritorial_toamna 2019.pdf

Cohen-Cline, H., Turkheimer, E., \& Duncan, G. E. (2015). Access to green space, physical activity, and mental health: a twin study. Journal of Epidemiology and Community Health, 69(6), 523-529. doi: http://dx.doi.org/10.1136/jech2014-204667

Connor, K. M., \& Zhang, W. (2006). Resilience: Determinants, measurement, and treatment responsiveness. CNS spectrums, 11(S12), 5-12. doi: https://doi.org/10.1017/ S1092852900025797 
Cowling, B. J., Ng, D. M. W., Ip, D. K. M., Liao, Q., Lam, W. W. T., Wu, J. T., Lau, J. T. F., Griffiths, S. M., \& Fielding, R. (2010). Community psychological and behavioural responses through the first wave of the 2009 influenza $\mathrm{A}(\mathrm{H} 1 \mathrm{~N} 1)$ pandemic in Hong Kong. The Journal of Infectious Diseases, 202(6), 867-876. doi: https://doi.org/10. 1086/655811

de Vries, S., Verheij, R. A., Groenewegen, P. P., \& Spreeuwenberg, P. (2003). Natural Environments-Healthy Environments? An Exploratory Analysis of the Relationship between Greenspace and Health. Environment and Planning A: Economy and Space, 35(10), 1717-1731. doi: https://doi.org/10.1068/a35111

Douglas, M., Katikireddi, S. V., Taulbut, M., McKee, M., \& McCartney, G. (2020). Mitigating the wider health effects of COVID-19 pandemic response. British Medical Journal, 369, 1-6. doi: https://doi.org/10.1136/bmj.m1557

Eisenberg, M. E., \& Resnick, M. D. (2006). Suicidality among Gay, Lesbian, and Bisexual Youth: The Role of Protective Factors. Journal of Adolescent Health, 39(5), 662-668. doi: https://doi.org/10.1016/j.jadohealth.2006.04.024

Fledderus, M., Bohlmeijer, E. T., \& Pieterse, M. E. (2010). Does experiential avoidance mediate the effects of maladaptive coping styles on psychopathology and mental health? Behaviour Modification, 34(6), 503-519. doi: https://doi.org/ $10.1177 / 0145445510378379$

Haddadi, P., \& Besharat, M. A. (2010). Resilience, vulnerability, and mental health. Procedia - Social and Behavioral Sciences, 5, 639-642. doi: https://doi.org/10.1016/j.sbspro. 2010.07.157

Hankin, B.L., Mermelstein, R., \& Roesch, L. (2007). Sex differences in adolescent depression: stress exposure and reactivity models. Child Development, 78(1). doi: https://doi. org/10.1111/j.1467-8624.2007.00997.x

Hardway, C., \& Fuligni, A. J. (2006). Dimensions of family connectedness among adolescents with Mexican, Chinese, and European backgrounds. Developmental Psychology, 42(6), 1246-1258. doi: https://doi.org/10.1037/0012-1649.42. 6.1246

Hegberg, N. J., \& Tone, E. B. (2015). Physical activity and stress resilience: Considering those at-risk for developing mental health problems. Mental Health and Physical Activity, 8, 17. doi: https://doi.org/10.1016/j.mhpa.2014.10.001

Hesketh, T., \& Ding, Q. J. (2005). Anxiety and depression in adolescents in urban and rural China. Psychological Reports, 96(2), 435-444. doi: https://doi.org/10.2466/pr0.96. 2.435-444

Hettema, J. M., Neale, M. C., \& Kenneth S., \& Kendler, K. S. (2001). A review and meta-analysis of the genetic epidemiology of anxiety disorders. The American Journal of Psychiatry, 158(10), 1568-1578. doi: https://doi.org/10.1176/ appi.ajp.158.10.1568

Huang, Y., \& Zhao, N. (2020). Generalized anxiety disorder, depressive symptoms, and sleep quality during the COVID-19 outbreak in China: a web-based cross-sectional survey. Psychiatry Research, 112954. doi: https://doi.org/10.1016/j.psychres.2020.112954

Iglesias, M. E. L., de Bengoa Vallejo, R. B., Salvadores Fuentes, P. (2010). The relationship between experiential avoidance and burnout syndrome in critical care nurses: A cross-sectional questionnaire survey. International Journal of Nursing Studies, 47(1), 30-37. doi: https://doi.org/10.1016/j. ijnurstu.2009.06.014.
INS (National Institute of Statistics). (2020). Starea economică şi socială a României 2017 şi 2018 - Date statistice. Available from: https://insse.ro/cms/sites/default/files/field/publicatii/starea_economica_si_sociala_a_romaniei_2020.pdf

Jacobson, K. C., \& Rowe, D. C. (1999). Genetic and environmental influences on the relationships between family connectedness, school connectedness, and adolescent depressed mood: Sex differences. Developmental Psychology, 35(4), 926-939. doi: https://doi.org/10.1037/0012-1649.35.4.926

James, P., Hart, J. E., Banay, R. F., \& Laden, F. (2016). Exposure to greenness and mortality in a nationwide prospective cohort study of women. Environmental health perspectives, 124(9), 1344-1352. doi: https://doi.org/10.1289/ehp. 1510363

Lamond, A. J., Depp, C. A., Allison, M., Langer, R., Reichstadt, J., Moore, D. J. (2008). Measurement and predictors of resilience among community-dwelling older women. Journal of Psychiatric Research, 43(2), 148-154. doi: 10.1016/j.jpsychires.2008.03.007

Law 351/ 6.07.2001. Available from: http://legislatie.just.ro/Public/DetaliiDocument/29780

Leal, P. C., Goes, T. C., da Silva, L. C. F., \& Teixeira-Silva, F. (2017). Trait vs state anxiety in different threatening situations. Trends in Psychiatry and Psychotherapy, 39(3), 147157. doi: https://doi.org/10.1590/2237-6089-2016-0044

Lister, R. G. (1990). Ethologically-based animal models of anxiety disorders. Pharmacology \& Therapeutics, 46(3), 321340. doi: https://doi.org/10.1016/0163-7258(90)90021-S

Luo, M., Guo, L., Yu, M., Jiang, W., \& Wang, H. (2020). The psychological and mental impact of coronavirus disease 2019 (COVID-19) on medical staff and general public - A systematic review and meta-analysis. Psychiatry Research, 291, 113190. doi: https://doi.org/10.1016/j.psychres. 2020.113190

Madhav, N., Oppenheim, B., Gallivan, M., Mulembakani, P., Rubin, E., \& Wolfe, N. (2017). Chapter 17. Pandemics: risks, impacts, and mitigation. In Jamison, D. T., Gelband, H., Horton S, Jha, P., Laxminarayan, R., Mock, G. N. \& Nugent, R. (Eds). Disease control priorities: improving health and reducing poverty. 3rd edition. The International Bank for Reconstruction and Development/The World Bank. doi: https://doi.org/10.1596/978-1-4648-0527-1 ch17

Mahoney, C. T., Segal, D. L., \& Coolidge, F. L. (2015). Anxiety sensitivity, experiential avoidance, and mindfulness among younger and older adults: age differences in risk factors for anxiety symptoms. The International Journal of Aging and Human Development, 81(4), 217-240. doi: https://doi. org/10.1177/0091415015621309.

Malaquias, S., Crespo, C., \& Francisco, R. (2015). How do adolescents benefit from family rituals? Links to social connectedness, depression, and anxiety. Journal of Child and Family Studies, 24(10), 3009-3017. doi: https://doi.org/ 10.1007/s10826-014-0104-4.

McKee-Ryan, F., Song, Z., Wanberg, C. R., \& Kinicki, A. J. (2005). Psychological and physical well-being during unemployment: a meta-analytic study. Journal of Applied Psychology, 90(1), 53. doi: https://doi.org/10.1037/00219010.90.1.53

McKenzie, K., Murray, A., \& Booth, T. (2013). Do urban environments increase the risk of anxiety, depression, and psychosis? An epidemiological study. Journal of affective disorders, 150(3), 1019-1024. https://doi.org/10.1016/j.jad. 2013.05.032 
Min, J. A., Lee, N. B., Lee, C. U., Lee, C., \& Chae, J. H. (2012). Low trait anxiety, high resilience, and their interaction as possible predictors for treatment response in patients with depression. Journal of affective disorders, 137(1-3), 61-69. doi: https://doi.org/10.1016/j.jad.2011.12.026

Minnesota Student Survey (2004). Available from: https://www.health.state.mn.us/data/mchs/surveys/mss/docs /countytables/countycover04.pdf

Moghanibashi-Mansourieh, A. (2020). Assessing the anxiety level of Iranian general population during the COVID-19 outbreak. Asian Journal of Psychiatry, 51, 1-5. doi: https://doi.org/10.1016/j.ajp.2020.102076

Pagel, J. I., \& Choukèr, A. (2016). Effects of isolation and confinement on humans-implications for manned space explorations. Journal of Applied Physiology, 120 (12), 1449-1457. doi: https://doi.org/10.1152/japplphysiol.00928.2015

Roya, A. (2017). Mediating role of interpersonal problems in the relationship between experiential avoidance with depression and anxiety. Journal of Applied Psychology, 4(40), 523-542.

Sanad, H. M. (2019). Stress and anxiety among junior nursing students during the initial clinical Training: a descriptive study at college of health sciences. American Journal of Nursing Research, 7(6), 995-999. doi: 10.12691/ajnr-7-6-13

Saviola, F., Pappaianni, E., Monti, A., Gregucci, A., Jovicich, J., \& De Pisapia, N. (2020). Trait and state anxiety are mapped differently in the human brain. Scientific Reports, 10(1). doi: https://doi.org/10.1038/s41598-020-68008-z

Savitsky, B., Findling, Y., Ereli, A., \& Hendel, T. (2020). Anxiety and coping strategies among nursing students during the COVID-19 pandemic. Nurse Education in Practice, 102809. doi: https://doi.org/10.1016/j.nepr.2020.102809

Schiele, M. A., \& Domschke, K. (2018). Epigenetics at the crossroads between genes, environment and resilience in anxiety disorders. Genes, Brain and Behavior, 17, 1-15. doi: https://doi.org/10.1111/gbb.12423

Shi, R., Zhang, S., Zhang, Q., Fu, S., Wang, Z. (2016). Experiential avoidance mediates the association between emotion regulation abilities and loneliness. PLoS One, 11(12): e0168536. doi: https://doi.org/10.1371/journal.pone. 0168536

Southwick, S. M., Vythilingam, M., \& Charney, D. S. (2005). The psychobiology of depression and resilience to stress: implications for prevention and treatment. Annual Review of Clinical Psychology, 1, 255-291. doi: https:// doi.org/10.1146/annurev.clinpsy.1.102803.143948

Spielberger, C. D. (1983). State-Trait Anxiety Inventory for Adults (STAI-AD). doi: https://doi.org/10.1037/t06496-000

Sylvester, C. M., Corbetta, M., Raichle, M. E., Rodebaugh, T., Schlaggar, B. L., Sheline, Y. I., Zorumski, C. F., \& Lenze, E. J. (2012). Functional network dysfunction in anxiety and anxiety disorders. Trends in Neuroscience, 35(9), 527-535. doi: https://doi.org/10.1016/j.tins.2012.04.012

Taquet., M., Luciano, S., Geddes, J. R., \& Harrison, P. J. (2020). Bidirectional associations between COVID-19 and psychiatric disorder: retrospective cohort studies of 62354
COVID-19 cases in the USA. The Lancet - Psychiatry. doi: https://doi.org/10.1016/ S2215-0366(20)30462-4

Thompson, C. W., Roe, J., Aspinall, P., Mitchell, R., Clow, A., \& Miller, D. (2012). More green space is linked to less stress in deprived communities: Evidence from salivary cortisol patterns. Landscape and urban planning, 105(3), 221-229. doi: https://doi.org/10.1016/j.landurbplan.2011.12.015

To, K. K. W., Hung, I. F. N., Ip, J. D., Chu, A. W. H., Chan, W. M., Tam, A. R., Fong, C. H. Y., Yuan, S., Tsoi, H. W., Ng, A. C. K., Lee, L. L. Y., Wan, P., Tso, E., Wing-Kin To, W. K., Tsang, D., Chan, K. Y., Huang, J. D., Kok, K. H., Cheng, V. C. C., Yuen, K. Y. (2020). COVID-19 reinfection by a phylogenetically distinct SARS-coronavirus-2 strain confirmed by whole-genome sequencing. Clinical Infectious Diseases [published online ahead of print, 2020 Aug 25], ciaa1275. doi: https://doi.org/10.1093/cid/ciaa1275

Verheij, R. A. (1996). Explaining urban-rural variations in health: A review of interactions between individual and environment. Social Science \& Medicine, 42(60), 923-935. doi: https://doi.org/10.1016/0277-9536(95)00190-5

Wainer, J., \& Chesters, J. (2000). Rural mental health: neither romanticism nor despair. The Australian Journal of Rural Health, 8, 141-147. doi: https://doi.org/10.1046/j.14401584.2000.00304.X

Walters, K., Breeze, E., Wilkinson, P., Price, G. M., Bulpitt, C. J., \& Fletcher, A. (2004). Local area deprivation and urbanrural differences in anxiety and depression among people older than 75 years in Britain. American Journal of Public Health, 94(10), 1768-1774. doi: https://doi.org/10.2105/ AJPH.94.10.1768

Ward, D. (2000). Infection control: reducing the psychological effects of isolation. British Journal of Nursing, 9(3), 162170. doi: https://doi.org/10.12968/bjon.2000.9.3.162

Wheaton, M. G., Deacon, B. J., McGrath, P. B., Berman, N. C., \& Abramowitz, J. S. (2012). Dimensions of anxiety sensitivity in the anxiety disorders: Evaluation of the ASI-3. Journal of Anxiety Disorders, 26(3), 401-408. doi: https://doi.org/10.1016/j.janxdis.2012.01.002

White, M. P., Alcock, I., Wheeler, B. W., \& Depledge, M. H. (2013). Would you be happier living in a greener urban area? A fixed-effects analysis of panel data. Psychological Science, 24(6), 920-928. doi: https://doi.org/10.1177/ 0956797612464659

Zerbe M. B., Parkerson, S. G., \& Spitzer, T. (1994). Laminar airflow versus reverse isolation: nurses' assessments of moods, behavior, and activity levels in patients receiving bone marrow transplants. Oncology Nursing Forum, 21(3), 565-568. doi: https://europepmc.org/article/med/8052552

Zhang, M., Zhang, J., Zhang, F., Zhang, L., \& Feng, D. (2018). Prevalence of psychological distress and the effects of resilience and perceived social support among Chinese college students: Does gender make a difference? Psychiatry Research, 267, 409-413. doi: https://doi.org/10.1016/j.psychres.2018.06.038 